\title{
Sympathy for Nature in Contemporary Ethical Discourse*
}

\author{
Aleksey Chernyak \\ Faculty of Humanities and Social Sciences \\ Peoples' Friendship University of Russia (RUDN \\ University) \\ 6 Miklukho-Maklaya Street \\ Moscow, Russian Federation 117198 \\ E-mail: abishot2100@yandex.ru
}

\author{
Svetlana Rudanovskaya \\ Faculty of Humanities and Social Sciences \\ Peoples' Friendship University of Russia (RUDN \\ University) \\ 6 Miklukho-Maklaya Street \\ Moscow, Russian Federation 117198 \\ E-mail: rudsv@live.ru
}

\begin{abstract}
Sympathy for nature is an essential component of ecological thinking, and a sign of ethical perception of nature. The proposed paper analyzes the ways nature is understood and treated in J. Bentham's utilitarianism, ethics of A. Schweitzer, and ecological ethics of A. Leopold, especially the motives of sympathetic and careful attitude towards it which may be observed within these approaches. The main question the authors seek to answer is: to what extent sympathy for nature may be free from egocentric attitudes and preoccupation with human problems and demands? They find that there is a tendency within contemporary ecological thinking to free itself from both: purely utilitarian vision of nature, and paternalistic attitude toward it.
\end{abstract}

Keywords-sympathy for nature; careful treatment of nature; utilitarianism; ethics of reverence for life; ecological ethics; ecological thinking

\section{INTRODUCTION}

One may suppose that ecological thinking is linked directly with sympathetic attitude toward nature which is impossible if people perceive nature either as some supreme autonomous power which does not need to be cared about by human beings, or as a source of supplies to be used to satisfy human wants. Sympathy presupposes seeing another living being as needing help and support, and is an expression of attention to the interests and needs which this being has in current situation. The relation of sympathy appears toward those who are in trouble or keep acting, achieving his or her goals in spite of hardships and limitations. Generally people sympathize with those who meet problems or risks, in particular the risk to cease to be themselves or to lose some important opportunities (such as the one of self-realization). In this case nature is understood as another being which is systematically ignored, suppressed, and included in foreign systems of ends and values. Sympathy of this sort is accompanied by critical self-consciousness turning into the sense of guilt, aspiration to abstain from usual human

*This paper was financially supported by the Ministry of Education and Science of the Russian Federation on the program to improve the competitiveness of Peoples' Friendship University of Russia (RUDN University) among the world's leading research and education centers in the 2016-2020. (The Agreement number 02.A03.21.0008). activities aimed at transformation of natural world, from realization of human projects at the expense of it.

Meanwhile, sympathy for nature is built on the convergence of peoples' beliefs about good for themselves with that which is the good for nature itself from the human point of view. The big deal of this convergence is connected with the peculiarities of sympathetic attitude which on the one hand overcomes egocentric closeness of individuals, their senselessness to whatever does not concern them or their relatives, and on the other hand may be the consequence of existing sympathy, sense of intimacy, and intuitively conceived likeness to the object of sympathy. Within sympathy an understanding of other being comes from an understanding of his or her situation which the sympathetic person wouldn't want to face or which is regarded as really problematic, complex, requiring participation of other people. ${ }^{1}$ In any case this situation doesn't leave a person indifferent. Feeling sympathy we do not necessarily see the world through the eyes of the other or feels what he or she feels (as it happens when empathy takes place), but we are sincerely interested in what is good for the other, compare this good with our own, and, as a result, agree with evaluations and emotional reactions of the other on what is going on. Doing this we stress the importance of such feelings and cares, impossibility of their ignorance, experience "delight in [other persons'] joys and grief at their sorrow" [2]. Taking care of the other's circumstances we are already instructed by some preunderstanding of his or her situation on the basis of our own value coordinates.

In a sense people always valued nature so far as they valued its gifts. But this recognition of the value of nature was not always sympathetic or coming from taking into account what is good for nature itself. Where nature was reduced to materials, resources, and means of human activity it could not be an object of genuinely sympathetic attitude; only economic care about rational use of resources took place. Subject can feel sorry about the object of such attitude; this may be identified as a superficial sympathy, sympathy

This understanding of sympathy distinguishes it from empathy. About empathy and related notions see, e.g. [1] 
from the distance without any desire to occupy the point of view of the object of such feeling, recognize its own significance. $^{2}$

\section{ATTITUDE TOWARD ANIMALS IN JEREMY BENTHAM'S UTILITARIANISM}

One of the first attempts to overcome instrumentally indifferent treatment of nature in Western philosophy was made by Jeremy Bentham. ${ }^{3}$ The beginner of Utilitarianism thought that moral attitude to other living beings is possible if we take into account their basic wants, i.e. to get pleasure and avoid that which is opposite to it (pain and suffering) [3]. These basic wants determine both the behavior of animals and activity of human beings; an understanding of these wants allows us to understand actions of living beings whichever biological species they belong. But utilitarian morality is based not on sympathy, but rather on evaluation of the consequences of actions for other beings from the point of view of the maxim of the greatest happiness of the greatest number. A person must try to minimize sufferings of living beings, but also he or she must give priority to human wants and problems. If human sufferings may be reduced at the expense of experiments on members of other biological species, these experiments are justified and even morally vindicated [4].

Nature in this case is on the one hand included into the sphere of moral evaluations (cruel treatment of animals which is not justified is morally condemned), but on the other hand these evaluations are subordinated not to the sympathy, but to the thorough reasoning about the utility for human beings. Sympathy for nature must not be stronger than sympathy for humans, which does not exclude the possibility of equal sympathy for any living and suffering creature by analogy with human beings (inequality appears when we choose what to do, taking happiness of humans as a supreme value). If we presume this, then active sympathy that influences human choice may be fully realized only when nothing threats humans or human wants are satisfied. It may be said that Bentham translates into the language of rationality some common sense beliefs according to which a man or a woman must provide his or her own safe existence, and let other beings live if possible. Developing his thoughts, we may say that unjustified cruelty is senseless because it gives happiness to no one; but extreme sympathy for animals is also senseless because it makes us forget our own happiness.

But Bentham's views of utility for humans cannot throw sufferings of other creatures into the background. From utilitarian point of view a person must intend happiness of

\footnotetext{
2 One even can continue making harm to the object of such feeling if he or she sees it as necessary.

In this paragraph we are talking about ethical approaches to nature, that generate not only theories of the essence of the world of nature, but also the ways of practical interaction with the environment. Along with Bentham's theory in the end of XVIII, in the first half of XIX century new philosophical accounts appear which stress the primordial significance of nature, its specific life force, and concealed link with the world of spirit and reason (romantics such as Goethe, Hölderline, Schelling, as well as Hegel who saw nature as a regular result of the formation of absolute spirit).
}

the majority of people, but this does not mean that his or her choice of methods for achieving happiness is absolutely indifferent to the needs of other living beings. In this sense Bentham's position is not the same as that of exploitation of nature. The priority of utility for people cannot prevent them to feel sympathy for other living beings, treat their sufferings as if they are similar to our own.

\section{ETHICS OF REVERENCE FOR LIFE OF ALBERT SCHWEITZER}

An important attempt to go beyond utilitarian treatment of nature in XX century is ethics of reverence for life of A. Schweitzer. In the focus of this account there is a person who sharply feels the diversity of life manifestations which are not differentiated between conscious and unconscious, developed and primitive, more and less significant in the structure of existence. Every life is significant, and, as a result, does make difference to the humans who have to be supersensitive to any crippling of living others, to any threat to their existence. "He tears no leaf from a tree, plucks no flower, and takes care to crush no insect. If in summer he is working by lamplight, he prefers to keep his windows shut and breathe a stuffy atmosphere rather than see one insect after another fall with singed wings upon his table" [5].

Reverence for life, on the one hand, "revives" the world around, filling it with different voices, feelings, invincible desire to be, and in this sense erases the borders between human and non-humans spaces. And on the other hand, the solidarity with "life which wants to live", understanding of life from within makes one submerge into the world of pain where different creatures constantly suffer from this or that violating act, lives are destroyed and aborted. The mind of the sympathizing person in this context transcends the borders between the living and non-living things settled by custom and tradition, and at the same time actualizes an importance of the other, which stays unseen in the context of ordinary anthropocentric perception of reality.

Speaking about sympathy A. Schweitzer does not absolutely reject the instrumental activity which one way or another ignores peculiarity of individual life. A person does not have a choice: to sympathize or to act. According to Schweitzer when engaged in any action a person should feel compassion for those who are in the field of his or her influence. "Those who experiment with operations or the use of drugs upon animals or inoculate them with diseases so as to be able to bring help to mankind with the results gained must never quiet any misgivings they feel with the general reflection that their cruel proceedings aim at a valuable result" [6]. Not the rejection of activity as such but the rejection of the passion for the practices, which atrophy the sense of other living creatures with their feelings, becomes the main guide for this worldview. According to Schweitzer sympathy presupposes inability and reluctance to abstract from sufferings of others even if these sufferings are justified by economical interests and humanistic considerations. Such sympathy is not secondary to some rationally justified position, but rather is a source of any further ethical claims. According to Schweitzer feeling the presence of another living being as living one is a natural condition of human 
person, and what is opposite to it (indifference, abstraction, atrocity) is in a sense an oblivion of this initial openness to the external world.

The openness and sensitivity, Schweitzer believes, do not make a person less adaptive to the world where it is necessary to make fast decisions, act professionally, rest periodically from the problems and sufferings of others. Certainly such sensitivity presupposes the reception of reality where besides successfully done job or good rest, besides our own tribe with whom everything is all right, there are different others requiring attention, being in distress. To sympathize is to feel responsibility for the future of other beings, to forget about "good conscience", about state of internal comfort provided by personal achievements and wellbeing. In the same time, sympathy does not exhaust human person, but gives his or her life the meaning comparable with the religious one. According to Schweitzer the sympathetic person feels solidarity with the endless will for life, establishes this will here and now, and at the same time recognizes his or her unity with the power which exceeds his or her individual possibilities. That's why sympathy is accompanied by one's readiness to live all out to serve the highest purpose and be stronger than circumstances which force people to feel satisfied with their lives.

We can agree with Schweitzer when he writes that "my knowledge of the world becomes experience of the world" [7]. But not every kind of knowledge loaded with experience will be sympathetic: we can experience the world as foreign to us or too variable, or completely autonomous, full of gods etc. Utilitarianism teaches us that one cannot live in the world taking into account only its present state: a reasonable person has to take care about feelings of other biological species' members here and now, but simultaneously think about human future. Ethics of reverence for life focuses on the possibility for any rational person to sense the mystery of life in every present moment, feel solidarity with others here and now, not to sacrifice the present to the future. Within ethics of Schweitzer the position of human being is not privileged, but it has some advantages. The main of them is the ability of homo sapience to notice different phenomena of life and to respond to them. However this very advantage charges persons with additional responsibilities.

\section{ECOLOGICAL ETHICS OF ALDO LEOPOLD}

Ecology as a science starts not with a sympathetic attitude toward nature, but with an intention to overcome the ordinary perceptions developed under the influence of an industrial way of life. According to these perceptions nature is something which is always at hand and serves as an unlimited field of human activity. An ecologist, guided by a specialized knowledge of natural world as a complex system of interrelated parts, sees things which are invisible to untrained eyes. Where the man in the street, the modern economic man (producer or/and consumer) sees no problem, the ecologist notices the symptoms of destabilization, decay or disease. "And there is an infinity of obscure connections in ecology, most of them unknowable" to the general public [8]. "Much of the damage inflicted on land is quite invisible to laymen" [9]. Like a doctor an ecologist raises alarm the moment, when there seems to be no reasons for anxiety. Against the background of technological progress and widespread sense of our independence from nature, ecology returns human beings to the awareness of their dependence on the biosphere and therefore reminds people that they live in the space of both social and biological ties. Moreover, in this space humankind has undergone rapid changes with often indefinite and uncontrollable consequences despite the definite purposeful activity which engenders them. In this sense human activity creates unfavorable living conditions for humans themselves.

Ecological texts of XX century make the main emphasis on the fact that existence of homo sapiens is not guaranteed and depends on the state of biosphere. In this case a person has to feel the situation of common destiny, interdependence with other creatures, common dangers that can be avoided by use of modern technologies, human ingenuity and imagination. This approach overcomes an economic stereotype of nature as human property, but leaves intact the belief that environment has to serve people and provide the existence of homo sapience by realizing certain functions. The idea of "nature-for-humans" appears now not in the context of economic production and consumption of material goods, but in the context of conservation of habitual environment. It is the ecological consciousness that stresses the possibility of losing the living space in the future and appeals to the human needs of survival and reason to avoid the most essential loss. The ecological consciousness anticipates factors and situations (resulting from social activity) that can negate all human efforts to make social progress. That's why human projects, according to ecology, should be elaborated with regard to biological knowledge and foreseeable future risks. It is better to make oneself safe today than to face the unfavorable irreversible changes tomorrow. Sympathy for nature in this frame is, above all, sympathy for humans and their future, the many threatening signs of which are observable nowadays.

Such sympathy fraught with primarily concern for one's own future and the intention to act ahead of time is also found in classical works on environmental ethics. For example Aldo Leopold directly addresses a human manager and his/her ability to provide stable functioning of a complex natural mechanism: "To keep every cog and wheel is the first precaution of intelligent tinkering" [10]. However this comparison is indispensable if we need to draw attention to "non-commodity" and economically "useless" natural objects, make people understand ecological problems at least in terms of the language of engineers, if the language of ethics turns out to be incomprehensible.

Simultaneously A. Leopold is one of the first thinkers who justifies an ethical attitude towards nature (free from economic interests and feelings of superiority) on the basis of ecological knowledge. A human being is "a member of community of interdependent parts", which includes "soils, waters, plants, and animals, or collectively: the land" [11]. Enjoying no privileged position, a person should coordinate his/her actions with other members of the community, not because it is beneficial to him/her, but because others exist and demand recognition of their existence. The land ethics 
elaborated by A. Leopold is directed against a selective treatment of our environment, since this attitude is based on human preferences and the notion of human utility. According to the author and his fellow thinkers, a contemporary politics of conservation is determined by "ranking systems", which enforce people to regard some species or territories as worthy of care while exploit others as they like $[12]^{4}$. On the contrary, the land ethics doesn't arrange the world in accordance with the level of utility for humans, but presumes equal significance of everything from the point of view of "big whole", a biological community.

In order to understand all components of nature as equally important, a human being should become more human to the world around him, surpass the inclination to see one thing and disregard the other. In this sense a human being should dispose of the idea that everything that doesn't concern him is not significant and has no reasons to exist. The imperative of ecological ethics requires a benevolent and "accepting" attitude towards diversity of nature which deserves human attention as well as every one who is close and dear to us. Besides, this attention should embrace both a big whole and its individual parts. It is in this connection that A. Leopold introduces an image of nature as a friend we can't be indifferent to: "Harmony with land is like harmony with a friend; you cannot cherish his right hand and chop off his left" [14]. But this image, taken by itself, is not enough to understand nature and its ties, on the contrary it inspires people to accept nature as too human-like, too close and encourages free, hob-and-nob treatment of environment. In order to avoid this simplification a person has to learn to see nature not only through anthropo- or socio-morphous images (of a friend or a community), which imply equal relations, but at the same time give way to paternalism. Alternative to those images is a picture of "powerful nature" that doesn't need human ward, condescension or overall control.

That's why Leopold adds one more meaningful image of nature - "the land pyramid" that is above human abilities, self-regulated and independent from multiple human caprices. Nature is a grand ensemble of lots of species and components, an organism which is able to adapt itself to different circumstances by changing its composition, but maintaining the complex structure and breathe of life - "a sustained circuit of energy" (A.Leopold). Handling nature this way, a person may experience something similar to admiration for (or worship of) the magnificent structure, where everything is wisely arranged and made useful as for individual species so for the entire biological community as a whole. Equally we should not forget that this magnificent structure is a living organism, which, like any organism, is vulnerable and has got limited stock of energy. Hence there arises a demand in ethical, responsible attitude towards this organism. We have to care about nature not because it is weak and we can run it as we like, but we have to care about it because it is alive and liable to dangers and risks which we equipped with our knowledge can prevent. In the framework of ecological ethics a human being should get rid of

As Aldo Leopold writes, 'In many instances the abuse of private land is worse than it was before we started" [13]. paternalistic account of nature and at the same time realize that his/her instrumental activities are a load on the biological realm. "Evolutionary changes... are usually slow and local. Man's invention of tools has enabled him to make changes of unprecedented violence, rapidity, and scope [...] The land recovers, but at some reduced level of complexity, and with a reduced carrying capacity for people, plants, and animals" [15].

With ecology and ecological ethics humans learn living in the small, "compact world", where besides their species there are lots of others influenced by the consequences of human activities. Ecological discourse, essentially critical, reveals the wrong side of social progress and demonstrates that a human creator may be a potential destructor of biological infrastructure (soils, water, air, biological diversity), threatening the very process of life. So the key end of ecology is to describe a global risk situation in society which prefers to go on as if no dangers existed. From the ethical point of view ecology does not require a radical "revaluation of values" (to forget about human perspectives and devote oneself entirely to an enterprise of nature salvation). But it demands to extend a human system of values with new ones, specifically: a value of big biological whole and a value of life which is multiform and far from being a thing we can use, throw away and forget.

In spite of the fact that A. Leopold's ecological ethic appeals not to feelings, but to reason, it presupposes no less attention to the surrounding world than A. Schweitzer's ethical approach and confirms attention which is impossible without emotional involvement in problems of others ${ }^{5}$. However A. Leopold doesn't make the main emphasis on care that can protect nature from any violent act, human intervention into individual lives. The founder of ethical approach in ecology stresses the necessity of careful attitude towards a complicated structure of biological organism together with natural diversity which can vanish into thin air not only under the influence of human-oriented projects, but under the impact of various "nature conservation" practices (carried out without adequate understanding). The most important thing in a land ethic is a necessity to understand nature (its simultaneous dependence and independence from sociosphere) and everybody's responsibility for the infrastructure of biological community, which is indispensable for life and any ethical reflections over it. "A land ethic, - A. Leopold writes, - reflects the existence of an ecological conscience, and this in turn reflects a conviction of individual responsibility for the health of the land. Health is the capacity of the land for self-renewal. Conservation is our effort to understand and preserve this capacity" [17].

\section{CONCLUSION}

Feeling sympathy for nature we presume that nature as a whole or in some of its parts has needs and experiences deficits, and aims at realization of its potential. From this point of view nature does not look an alien or secondary reality, or a system of stable objects which are always at

5 "We can be ethical only in relation to something we can see, feel, understand, love, or otherwise have faith in" [16]. 
hand. Rather nature is perceived as a living developing organism that comes through positive and negative states, has its "painful points" which may be understood in terms of human-like quality of life. Feeling sympathy to nature we presume common living conditions which directly determine our experience of existence in the world and are considered as good for biological organisms (life and health in opposition to death and illness, possibility of growth and development in opposition to suppression and interruption of evolution).

Feeling sympathy for nature in this sense we perceive it as a valuable subject whose interests and ends are worthy of our care and participation. Such attitude is at the core of a value reference of contemporary ecological thinking, and is a starting point for critical reconsideration of a series of stereotypes spread within ordinary, primitive reception of ecological problems. One of these stereotypes is anthropocentric perception of nature when it is treated as a mere foundation of habitual zone of human comfort without which we cannot live. Another stereotype is paternalistic vision of nature as something passive, not autonomous, which needs human guardianship and guidance. Both stereotypes create strong motivation to solve ecological problems, but at the same time they make these problems worse, spread superficial and one-sided perception of reality. Anthropocentrically minded individual does not see anything which he or she does not consider good for him or her, as paternalist he or she does not notice the redundancy and inadequacy of certain security measures (such as, e.g., protection of some kinds of animals at the expense of some others). Essentially, being engaged in conservation, people can exhibit not less indifference to its diversity and potential as they do when they just use nature, involving it into the sphere of mass production of material goods oriented on customers' requests.

Ethical discourse, starting with J. Bentham, includes natural organisms in the sphere of human care and attention, change not only the common worldview, but also the scope and level of human responsiveness to sufferings of other living beings. In comparison with ethics of A. Schweitzer utilitarianism and ecological discourse are less grounded in "language of senses", but they address more rational knowledge of utility (in utilitarianism) or of possible risks (in ecology). However ecological ethics of A. Leopold, as well as ethics of A. Schweitzer, requires constant attention to nature no matter how this attention relates to human happiness or pain, possible advantages and losses, because any advantage and loss is determined by one-sided anthropocentric vision of reality. It does not mean that people can and must forget their own interests, but it does mean that they should measure and correct these interests in a wider context including not only other people and social subjects, but also world of nature, alive in its diverse unique phenomena (A. Schweitzer), with changing system-making ties, not eternal (A. Leopold). Talking about the necessity of sympathetic and careful treatment of nature, subject-subject relations, ethical discourse this or that way emphasizes an ability of a person to consider him- or herself one of many subjects of existence (not the only one) and experience selfless interest in their being in the world. Following ecological ethics humans should limit their desires, demands for the sake of others whose significance is supposed to be undoubted for them both on the level of immediate emotional perception of individual lives and on the level of general worldview including the idea of a big biological community.

\section{REFERENCES}

[1] K. Stueber "Empathy", The Stanford Encyclopedia of Philosophy (Spring 2018 Edition), Edward N. Zalta (ed.), URL: https://plato.stanford.edu/archives/spr2018/entries/empathy/ (24.05.2018)

[2] S. Blackburn "Sympathy" // Blackburn, S. The Oxford Dictionary of Philosophy. Oxford, N.Y.: Oxford University Press, 1996. - p. 369.

[3] J. Bentham An Introduction to the Principles of Morals and Legislation. Kitchener: Batoche Books, 2000. - p. 14.

[4] J. Bentham "To the Editor of the Morning Chronicle"// Morning Chronicle. L, 1825. (9 March) - p. 2.

[5] A. Schweitzer Civilization and Ethics (selection) // Albert Schweitzer's Ethical Vision. A Sourcebook. Ed. by Predrag Cicovacki. Oxford, N.Y.: Oxford University Press, 2009. - p. 138.

[6] A. Schweitzer Civilization and Ethics (selection) // Albert Schweitzer's Ethical Vision. A Sourcebook. Ed. by Predrag Cicovacki. Oxford, N.Y.: Oxford University Press, 2009. - p. 144.

[7] A. Schweitzer Civilization and Ethics (selection) // Albert Schweitzer's Ethical Vision. A Sourcebook. Ed. by Predrag Cicovacki. Oxford, N.Y.: Oxford University Press, 2009. - p. 137.

[8] D. Ehrenfeld The Arrogance of Humanism. Oxford, N.Y.: Oxford University Press, 1981. - p. 191.

[9] A. Leopold Round River // Ecological Anthology. Ecological Writing from the West. Moscow-Boston: Golubka, 1992. - p. 50.

[10] A. Leopold Round River // Ecological Anthology. Ecological Writing from the West. Moscow-Boston: Golubka, 1992. - p. 48.

[11] A. Leopold Sand County Almanac and Sketches Here and There. Oxford, L., N.Y.: Oxford University Press, 1968. - p. 173.

[12] D. Ehrenfeld The Arrogance of Humanism. Oxford, N.Y.: Oxford University Press, 1981. - p. 202.

[13] A. Leopold Round River // Ecological Anthology. Ecological Writing from the West. Moscow-Boston: Golubka, 1992. - p. 50.

[14] A. Leopold Round River // Ecological Anthology. Ecological Writing from the West. Moscow-Boston: Golubka, 1992. - p. 48.

[15] A. Leopold Sand County Almanac and Sketches Here and There. Oxford, L., N.Y.: Oxford University Press, 1968. - pp. 183-185.

[16] A. Leopold Sand County Almanac and Sketches Here and There. Oxford, L., N.Y.: Oxford University Press, 1968. - p. 181.

[17] A. Leopold Sand County Almanac and Sketches Here and There Oxford, L., N.Y.: Oxford University Press, 1968. - p. 186. 